\title{
The effect of different insertion techniques on the depth of cure and vickers surface micro-hardness of two bulk-fill resin composite materials
}

\author{
Lamiaa-Mahmoud Moharam ${ }^{1}$, Ahmed-Zohair El-Hoshy ${ }^{2}$, Karim Abou-Elenein ${ }^{2}$ \\ ${ }^{1}$ Restorative and Dental Materials Research department, National Research Centre, Giza, Egypt \\ ${ }^{2}$ Operative Dentistry department, Faculty of Oral and Dental medicine, Cairo, Egypt
}

\section{Correspondence:}

National Research Centre

33 El Bohouth st. (former El Tahrir st.)

Dokki, Giza, Egypt

lamia.moharam@gmail.com

Received: 06/07/2016 Accepted: 18/07/2016
Moharam LM, El-Hoshy AZ, Abou-Elenein K. The effect of different insertion techniques on the depth of cure and vickers surface microhardness of two bulk-fill resin composite materials. J Clin Exp Dent. 2017;9(2):e266-71.

http://www.medicinaoral.com/odo/volumenes/v9i2/jcedv9i2p266.pdf

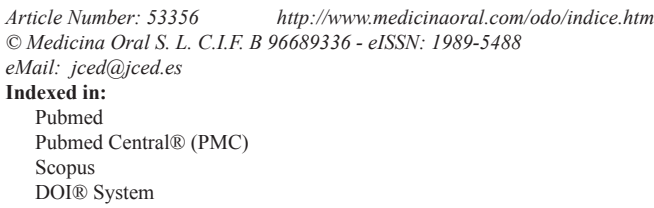

\begin{abstract}
Background: The aim of this study was to evaluate the Vickers surface micro-hardness and the depth of cure of two bulk-fill resin composites and one incremental-fill resin composite.

Material and Methods: Two Bulk-fill dental resin composites (X-tra Fil, Voco; Sonic-FillTM 2, Kerr Corporation) and an incremental-fill dental resin composite (Filtek ${ }^{\mathrm{TM}}$ Z250 XT, 3M ESPE) were used. Sixty cylindrical specimens of $4 \mathrm{~mm}$ thickness were prepared using split Teflon moulds. Specimens were divided into six groups $(\mathrm{n}=10)$ according to the type of the material used and according to the insertion technique applied (bulk or incremental). Prepared specimens were stored dry in complete darkness at $37^{\circ} \mathrm{C}$ for 24 hours. All specimens were tested for their Vickers surface micro-hardness, on their top and bottom surfaces. The depth of cure of the tested specimens was assessed by calculating the hardness ratio for each specimen. The Vickers surface micro-hardness and depth of cure data were analyzed for normality using Kolmogorov-Smirnov and Shapiro-Wilk tests. Independent sample-t test was used to compare between two groups while One-way ANOVA was used to compare between more than two groups.

Results: Significant difference in the Vickers surface micro-hardness and depth of cure values was demonstrated among the tested materials $(P<0.0001)$. X-tra Fil recorded the highest mean Vickers micro-hardness value (94.05 \pm 1.05$)$. Bulk-fill dental resin composites X-tra Fil and Sonic-Fill showed $0.980 \pm 0.005$ and $0.921 \pm 0.020$ depth of cure values (bottom/top hardness ratio) respectively while Z250 XT recorded 0.776 \pm 0.141 .

Conclusions: X-tra Fil showed highest Vickers surface micro-hardness values on both top and bottom surfaces, whether inserted in increments or bulk. Both bulk-fill resin composites showed higher depth of cure for both insertion techniques.
\end{abstract}

Key words: Depth of cure, Vickers surface micro-hardness, bulk-fill resin composite, insertion techniques. 


\section{Introduction}

Restoring prepared dental cavities with light-curing resin composites has been regarded as the gold standard. However, to apply and cure the resin composite in successive increments of limited thickness has shown to be time-consuming and increase the risk of incorporating oral fluids within the increments, (1) which adversely affects the mechanical and physical properties of the set material.

Recently, many dental practitioners prefer using more time-saving restorative procedures. Dental resin composite manufacturers, with a vision to simplify these procedures; have introduced a new category of dental resin composites, the so-called "bulk-fill" Materials, (2) that can be applied in a single increment (up to $4 \mathrm{~mm}$ ), reducing the clinical steps. Bulk-fill resin composite materials have high color translucency, allowing the incident light to penetrate deeper into the resin composite (3). The innovative system of polymerization-initiation that led to shortening of light-curing time and increasing the depth of cure. Low polymerization shrinkage of these materials together with their high filler content, resulted in very low polymerization which, allowed for application of thicker resin composite layers (4). Surface hardness measurement has shown to be a practical method to indirectly determine the degree of monomer conversion for resin composite materials. Furthermore; hardness profiles can be used to alternatively measure the depth of cure of such resinous materials (5).
Therefore; the objective of this study was to gain more insight about bulk-fill resin composite materials by analyzing the effect of different insertion techniques on the Vickers surface micro-hardness and the depth of cure of two different bulk-fill dental resin composite materials.

\section{Material and Methods}

This study has been approved by ethics committee. Two commercially available bulk-fill dental resin composites and one incremental-fill dental resin composite were used in the study. Materials' description, manufacturers and composition were listed in table 1.

-Study design and specimen grouping:

Sixty cylindrical specimens were prepared and assigned for the depth of cure and Vickers surface micro-hardness evaluation. Specimens were divided into six groups $(n=10 /$ group), representing the resin composite materials used in the study (two bulk-fill resin composites: Sonic-Fill ${ }^{\mathrm{TM}} 2$ [Sonic-Fill] and X-tra Fil [X-tra Fil]); one incremental-fill resin composite: Filtek ${ }^{\mathrm{TM}} \mathrm{Z} 250 \mathrm{XT}$ [Z250 XT]; and the two insertion techniques (bulk and incremental).

-Specimen preparation:

Split Teflon moulds of $4 \mathrm{~mm}$ diameter and $4 \mathrm{~mm}$ thickness were used to prepare the specimens. Each mould was encircled by a copper ring to provide stabilization during manipulation of the materials.

The moulds were first mounted on the top of a microscope slide and a clear Mylar strip, and then each mould was

Table 1. Materials description, composition and manufacturer.

\begin{tabular}{|c|c|c|c|}
\hline Material & Description & Composition & Manufacturer \\
\hline X-tra Fil & $\begin{array}{l}\text { Nano-Hybrid bulk-fill } \\
\text { resin composite }\end{array}$ & $\begin{array}{l}\text { Bis-GMA, UDMA, TEGDMA, Inorganic } \\
\text { fillers: } \mathrm{SiO}_{2} \text {, glass, oxide ( } 86 \mathrm{wt} \% / 70.1 \\
\text { vol } \%) .\end{array}$ & $\begin{array}{c}\text { Voco GmbH, } \\
\text { Cuxhaven, Germany. }\end{array}$ \\
\hline Sonic-Fill $^{\mathrm{TM}} 2$ & $\begin{array}{c}\text { Sonic- } \\
\text { activated } \\
\text { Single-Fill } \\
\text { resin } \\
\text { composite }\end{array}$ & $\begin{array}{l}\text { 10-30 wt } \% \text { Poly (oxy-1,2 ethanediyl), } \alpha, \alpha \text { - } \\
{[(1-\text { methylethylidene }) \text { di-4,1 phenylene }] \text { bis }} \\
{[\omega-[(2-\text { methyl -1- oxo-2- propenyl)oxy }]-0.1-} \\
1 \% 2,2 \text { - ethylenedioxydiethyl dimethacrylate }\end{array}$ & $\begin{array}{c}\text { Kerr Coporation, West Collins } \\
\text { Avenue, Orange, } \\
\text { California, USA. }\end{array}$ \\
\hline $\begin{array}{c}\text { Filtek }^{\mathrm{TM}} \\
\text { Z250 XT } \\
{[\mathrm{Z250} \text { XT] }}\end{array}$ & $\begin{array}{l}\text { Nano-Hybrid } \\
\text { Universal Restorative } \\
\text { Resin } \\
\text { composite }\end{array}$ & $\begin{array}{c}\text { 55-65 wt } \% \text { Water, 30-40 wt } \% \text { Phosphoric } \\
\text { Acid, 5-10 wt\% Synthetic Amorphous Silica, } \\
\text { Surface Modified Zerconia/Silica (0.1-10 } \\
\text { microns), } 20 \text { nm Surface Modified Silica } \\
\text { Particles, } 81.8 \text { wt\% Inorganic Filler (67.8 } \\
\text { vol.\%), Bis-GMA, UDMA, Bis-EMA, } \\
\text { PEGDMA, TEGDMA. }\end{array}$ & $\begin{array}{l}\text { 3M ESPE, } \\
\text { Dental Products Division, } \\
\text { St. Paul, MN, } \\
\text { USA }\end{array}$ \\
\hline
\end{tabular}

Bis-GMA=Bis-Phenol-A glycidyl-methacrylate, Bis-EMA=Ethoxylated bisphenol A dimethacrylate, UDMA=Urethane dimethacrylate, TEGDMA= Triethylene glycol dime-thacrylate, PEGDMA=Poly (ethylene glycol) dimethacrylate. 
filled with one of the three resin composites (Sonic-Fill, X-tra Fil and Z250 XT) according to the insertion techniques investigated in the study. For the bulk insertion technique; each mould was filled in a $4 \mathrm{~mm}$ single increment. While for the incremental insertion technique; the resin composite materials were inserted into the moulds in two successive increments ( $2 \mathrm{~mm}$ thickness each). The first resin composite increment was photo-polymerized using LED light curing unit (Elipar S10, 3M ESPE; USA) with a light intensity output of $1000 \mathrm{~mW} / \mathrm{cm}^{2}$ for 20 seconds as recommended by the manufacturers of the control resin composite material used in the study (Filtek Z250 XT nano-hybrid universal incremental-fill resin composite); then the second resin composite increment was inserted and packed over the previously photo-polymerized increment till the mould was slightly overpacked. The top surface of each mould was then covered using a second clear Mylar strip to avoid creation of the oxygen inhibited layer. A glass slide and a load of $1 \mathrm{~kg}$ was constantly held in place on the top of the second clear Mylar strip for 30 seconds to ensure consistent packing of the specimens and to obtain flat surface (6).

The top surface of each prepared specimen was photopolymerized using the light curing unit for 20 seconds. The guidance tip of the light curing unit was centered in $90^{\circ}$ angle to the top surface of the specimen and kept in a direct contact with the second Mylar strip. Light intensity output of the light curing unit was monitored using Demetron radiometer device [Model 100, Demetron Research Corporation, Danbury, CT, USA] (7) and then the cylindrical specimens were gently removed from the moulds and the excess resin composite material was removed using a sharp scalpel.

Top surface of each specimen was identified with a dark marker pen. Specimens were stored dry in tightly sealed containers and in complete darkness condition at $37^{\circ} \mathrm{C}$ for 24 hours to prevent the ambient light from causing post light-curing polymerization, (7) until the Vickers micro-hardness test was conducted and the depth of cure was calculated.
-Vickers surface micro-hardness testing:

Sixty specimens $(\mathrm{n}=10)$ were tested using Vickers micro-hardness testing machine (Nexsus 4503, INNOVATEST, Netherlands, Europe) (7). Three randomized indentations on the center of the top and the bottom surfaces of each specimen were made using a diamond, square-head indentor at $500 \mathrm{~g}$ load and 15 seconds dwell time. Calculations were made using computer software (Hardness-Course Vickers/ Brinell/ Rockwell copy right IBS 2012 version 10.4.4) (8).

-Depth of cure of the resin composites:

The depth of cure of the tested resin composites was assessed by calculating the hardness ratio for each specimen. It was calculated by dividing the mean Vickers hardness number (VHN) of the bottom surface by the mean (VHN) of the top surface for each specimen according to the equation: (9) Depth of cure (hardness ratio) $=$ VHN bottom surface / VHN top surface.

-Statistical analysis

Mean and standard deviation values were calculated for each group in each test. Data were explored for normality using Kolmogorov-Smirnov and Shapiro-Wilk tests. Independent sample-t test was used to compare between two groups while One-way ANOVA was used to compare between more than two groups. The significance level was set at $P \leq 0.05$. Statistical analysis was performed with IBM ${ }^{\circledR}$ SPSS ${ }^{\circledR}$ Statistics Version 20 for Windows.

\section{Results}

Means and standard deviations of Vickers surface micro-hardness for the evaluated groups were represented in table 2. Significant difference was demonstrated between the mean micro-hardness values of different groups at $P=0.001$. The top surface group of X-tra Fil bulk-fill resin composite when used in bulk insertion technique recorded the highest mean micro-hardness value $(95.16 \pm 0.44)$. However, the bottom surface group of Z250 XT recorded the lowest mean micro-hardness value when used in bulk insertion technique (57.16 \pm 0.69$)$. Mean and standard deviation values of the depth of

Table 2. One-way ANOVA representing the mean, standard deviation (SD) values of Vickers surface micro-hardness of the different tested groups.

\begin{tabular}{|c|c|c|c|c|}
\hline \multirow{2}{*}{ Variables } & \multicolumn{2}{|c|}{ Incremental insertion technique } & \multicolumn{2}{c|}{ Bulk insertion technique } \\
\cline { 2 - 5 } & $\begin{array}{c}\text { Top surface } \\
\text { (Mean } \pm \text { SD) }\end{array}$ & $\begin{array}{c}\text { Bottom surface } \\
(\text { Mean } \pm \text { SD) }\end{array}$ & $\begin{array}{c}\text { Top surface } \\
\text { (Mean } \pm \text { SD) }\end{array}$ & $\begin{array}{c}\text { Bottom surface } \\
\text { (Mean } \pm \text { SD) }\end{array}$ \\
\hline X-tra Fil & $94.84 \pm 0.18^{\mathrm{a}}$ & $93.27 \pm 0.27^{\mathrm{a}}$ & $95.16 \pm 0.44^{\mathrm{a}}$ & $92.94^{\mathrm{a}} \pm 0.53^{\mathrm{a}}$ \\
\hline Sonic-Fill & $89.64 \pm 0.34^{\mathrm{b}}$ & $84.02 \pm 0.13^{\mathrm{b}}$ & $89.01 \pm 0.61^{\mathrm{b}}$ & $80.53 \pm 1.05^{\mathrm{b}}$ \\
\hline Z250 XT & $90.19 \pm 0.29^{\mathrm{b}}$ & $81.66 \pm 0.23^{\mathrm{c}}$ & $88.29 \pm 0.26^{\mathrm{b}}$ & $57.16^{\mathrm{b}} \pm 0.69^{\mathrm{c}}$ \\
\hline P-value & \multicolumn{2}{|c|}{$\mathbf{0 . 0 0 1 *}^{\mathbf{0}}$} & $\mathbf{0 . 0 0 1 *}^{*}$ \\
\hline
\end{tabular}

Mean with different letters in the same column indicate statistically significance difference. ${ }^{*}$; significant $(p<0.05)$ ns; non-significant $(p>0.05)$. 
cure of the tested materials were represented in table 3. A statistically significant difference was demonstrated between the depth of cure values of different groups at $p=0.0001$. The highest mean depth of cure value was recorded for X-tra Fil bulk-fill resin composite when inserted incrementally $(0.983 \pm 0.001)$; while the lowest value was recorded for Z250 XT resin composite when inserted in bulk. lues recorded from the bottom surface, due to the difference in the monomer reactivity and filler/matrix refractive index mismatch (14).

In the present study, the mean micro-hardness values recorded on the bottom surfaces of Z250 XT were significantly decreased compared to the values recorded on the top surface; however, for X-tra Fil and Sonic-Fill bulkfill resin composite materials; the values of the micro-

Table 3. One-way ANOVA for the mean, standard deviation (SD) values of depth of cure of the different resin composite tested materials.

\begin{tabular}{|c|c|c|c|}
\hline Variables & $\begin{array}{c}\text { Incremental insertion technique } \\
(\text { Mean } \pm \text { SD) }\end{array}$ & $\begin{array}{c}\text { Bulk insertion technique } \\
(\text { Mean } \pm \text { SD) }\end{array}$ & P-value \\
\hline X-tra Fil & $0.983 \pm 0.001^{\mathrm{a}}$ & $0.976 \pm 0.006^{\mathrm{a}}$ & $\mathbf{0 . 1 7 n s}$ \\
\hline Sonic-Fill & $0.937 \pm 0.003^{\mathrm{b}}$ & $0.904 \pm 0.015^{\mathrm{b}}$ & $\mathbf{0 . 0 2}$ \\
\hline Z250 XT & $0.905 \pm 0.002^{\mathrm{c}}$ & $0.647 \pm 0.006^{\mathrm{c}}$ & $\mathbf{0 . 0 0 0 1 ^ { * }}$ \\
\hline P-value & $\mathbf{0 . 0 0 1 *}^{*}$ & $\mathbf{0 . 0 0 1 *}$ & \\
\hline
\end{tabular}

Mean with different letters in the same column indicate statistically significance difference. *; significant $(p<0.05)$ ns; non-significant $(p>0.05)$.

\section{Discussion}

In the present study, the highest mean surface microhardness value was recorded for the X-tra Fil bulk-fill resin composite material. Statistically significant differences were noticed in Vickers surface micro-hardness mean values among all tested resin composite materials and that was in agreement with the previous findings of Leprince et al. (10).

Such findings could be multi-factorial. One of these factors might be the difference in the chemical composition of the resin monomer, which was reported to affect the surface micro-hardness of the resin composites (7).

It was stated that, mass fractions, size as well as distribution of filler particles within the resin monomer have a significant positive effect on the different physical and mechanical properties of the resin composites, including surface hardness, depth of cure, the degree of conversion, flexure and compressive strength (11). Manufacturers of bulk-fill dental resin composites have clarified that these materials have higher filler particles content and thus have increased esthetic, physical and mechanical properties (12).

In the current study; different resin composite materials were applied in increments (single or multiple) and then each increment was photo-polymerized only from the topside in a way to mimic the actual clinical situation. This would eventually mean less resin composite matrix polymerization and, accordingly, a larger role of the filler particle type and percentage (content) in the material behavior (13).

It is expected for any resin composite material that its top surface micro-hardness value to differ from the va- hardness of the bottom surfaces were not statistically different from values registered for the top surfaces. The surface micro-hardness of resin composites was proved to be affected by increment thickness of the used resin composite material (7). In our study, two different insertion techniques of the resin composite materials were employed; which was expected to have the same effect on the surface micro-hardness at different specimen thickness. There was a decrease in the micro-hardness values on the bottom surfaces for all resin composite tested materials when bulk insertion technique was used. However; such change was only statistically significant for Z250 XT resin composite material.

The significant decrease in the surface micro-hardness of the $4 \mathrm{~mm}$ bulk inserted specimens of Z250 XT in this study were in agreement with a previous study (7) which reported that the resin Vickers hardness at the bottom surface was significantly different from that at the top surface when the specimens were placed in $4 \mathrm{~mm}$-thick increments. Such finding may be explained by the difference in translucency between the bulk-fill and the incrementally inserted dental resin composites. With a higher translucency, the bulk-fill resin composites might have allowed more of the photo-polymerizing light to penetrate deep inside the resin composite materials, which possibly could have caused more polymerization of the resin composites monomers (15). This was also confirmed by previous studies reporting that enhanced polymerization of bulk-fill composite is owed to their higher translucency due to the increase in their filler particle size (7).

The significant difference between the surface micro- 
hardness values of X-tra Fil and Sonic-Fill bulk-fill resin composite materials might be attributed to the difference in their monomer viscosity. It was reported that the flowable bulk fill resin composites showed lower surface micro-hardness values than the condensable bulk-fill resin composites (16). Sonic-Fill resin composite material incorporates a highly filled resin monomer with special modifiers that strongly react to the sonic energy. Whenever the sonic energy is applied, the modifier causes the monomer viscosity to drop (up to $87 \%$ ), increasing the flowability of the resin composite. Such drop might be responsible for the lower surface micro-hardness value (17).

Moreover, there are other parameters that might be responsible for the difference of surface micro-hardness values among the different tested materials including, filler particles morphology and distribution, (7) particle shape and density, monomer type and ratio, the degree of polymers cross-linking as well as the degree of conversion; which all vary greatly between the different products present in the market. A different study (18) showed that a ratio of $80 \%$ depth of cure has often been used as the minimum clinically acceptable value. In agreement with the results of other investigation (19) the hardness ratio of all materials tested in this study succeeded to fulfill this minimum value.

On the contrary, Z250 XT failed to fulfill this requirement when inserted in bulk. The higher depth of cure in bulk-fill resin composites could be owed to their higher translucency, as well as to their modified resin monomers and the recent photo-initiator systems $(7,15)$. It was reported that the translucency of resin composites depends on their thickness as well as the scattering and absorption coefficients of the resin filler particles $(7,13)$.

Some studies have shown that the translucency was decreased when the amount of the reinforcing filler particles was increased, (20) while it showed an increases when the reinforcing filler particles size was increased. This could be due to light scattering that happens within the resin composite matrix which might increase as the particle size of the filler approaches the wavelength of the activating light. It is well known that smaller filler particles scatter more light than larger filler particles (21). Such light scattering decreases the amount of the incident light which is transmitted throughout the resin composite and however interferes in a negative pattern with the physical and mechanical properties of the resin composites (22).

This was confirmed by results of the current study where Z250 XT showed significantly lower depth of cure than $\mathrm{X}$-tra Fil and Sonic-Fill. There is some other factor that might explain the differences in the depth of cure among the different tested resin composite materials; which is the resin monomer properties. Moreover; the viscosity of the resin monomer and the flexibility of its compositional chemical structure might influence the depth of cure of the resin composite material. In the current study, X-tra Fil showed significant higher depth of cure than that of the other tested materials. This might be due to the difference in the chemical composition of their organic resin matrix. The organic resin matrix of X-tra Fil is composed of Bis-GMA, UDMA, and TEGDMA. It was stated that the ultimate degree of monomer conversion of the different resin composite systems, regarding their compositional resin monomers, increases in the subsequent arrangement: Bis-GMA $<$ Bis-EMA $<$ UDMA $<$ TEGDMA (23).

Bis-GMA has a strong intra-molecular hydrogen bonding of its hydroxyl groups, in order that it is considered the most viscous and least flexible monomer among the other compositional dental resin monomers. UDMA has a hydrogen bond between its amine and carbonyl groups, and it is also a viscous resin monomer.

Nevertheless, the viscosity of UDMA is much lower in relation to that of Bis-GMA due to its weaker hydrogen bond. Additionally, amine groups presence in the urethane structure of UDMA monomer is considered to be responsible for the distinguishing chain transfer reactions that offer an alternative trail for the continuance of polymerization; therefore resulting in a promoted resin monomer conversion (24). This might explain the higher degree of conversion and depth of cure values of UDMA containing organic matrix of X-tra Fil. Although, Z250 XT organic matrix is similar to that of X-tra Fil but it recorded lower depth of cure. This is possibly due to the polymerization characteristics, which were significantly influenced by the difference in organic resin matrix chemistry and by the concentration of each resin monomer in the composite matrix (25). TEGDMA is considered to be a diluent monomer, as it has the lowest viscosity and the highest degree of monomer conversion among the different resin composite monomer systems. Therefore, when Bis-GMA is diluted with the low viscosity TEGDMA resin monomer, a synergistic effect has been significantly observed on the rate of polymerization, degree of monomer conversion as well as the depth of cure (26). Consequently, this might be another helpful factor that might explain the significant high depth of cure of the $\mathrm{X}$-tra Fil bulk-fill resin composite material since it may contain a higher concentration of TEGDMA monomer of resin composite.

When incremental insertion was used, a significantly higher depth of cure was noted compared to bulk insertion. Such results were confirmed by a previous study and might be related to the fact that specimens prepared with incremental packing received more total energy than those inserted in bulk (27). 


\section{Conclusions}

X-tra Fil bulk-fill resin composite material has showed the highest Vickers surface micro-harness values on both top and bottom surfaces of the tested specimens, whether inserted in increments or in bulk. Both bulk-fill resin composites (X-tra Fil and Sonic-Fill) showed higher depth of cure regarding both insertion techniques.

\section{References}

1. Peutzfeldt A, Asmussen E. Determinants of in vitro gap formation of resin composites. J Dent. 2004; 32:109-15.

2. Nagpal R, Manuja N, Tyagi S, Singh U. In vitro bonding effectiveness of self-etch adhesives with different application techniques: a microleakage and scanning electron microscopic study. J Conserv Dent. 2011; 14:258-63.

3. Tarle TA, Marovic D, Andermatt L, Ristic M, Tauböck T. Influence of irradiation time on subsurface degree of conversion and microhardness of high-viscosity bulk-fill resin composites. Clin Oral Investig. 2015;19:831-40.

4. Finan L, Palin WM, Moskwa N, McGinley EL, Fleming GJ. The influence of irradiation potential on the degree of conversion and mechanical properties of two bulk-fill flowable resin composite base materials. Dent Mater. 2013; 29:906-12.

5. Yan YL, Kim YK, Kim KH, Kwon TY. Changes in degree of conversion and microhardness of dental resin cements. Oper Dent. 2010;35:203-10.

6. Fleming G, Awan M, Cooper P, Sloan A. The potential of a resincomposite to be cured to a $4 \mathrm{~mm}$ depth. Dent Mat. 2008;24:522-9.

7. Nagi SM, Moharam LM, Zaazou MH. Effect of resin thickness, and curing time on the micro-hardness of bulk-fill resin composites. J Clin Exp Dent. 2015;7:e600-4.

8. Bhalla M, Patel D, Shashikiran ND, Mallikarjuna RM, Nalawade TM, Reddy HK. Effect of light- emitting diode and halogen light curing on the micro-hardness of dental composite and resin-modified glass ionomer cement: An in vitro study. J Ind Soc Ped Prev Dent. 2012;30:201-5.

9. Poggio C, Lombardini M, Gaviati S, Chiesa M. Evaluation of Vickers hardness and depth of cure of six composite resins photo-activated with different polymerization modes. J Conserv Dent. 2012;15:23741.

10. Leprince JG, Palin WM, Vanacker J, Sabbsgh J, Devaux J,Leloup G. Physico-mechanical characteristics of commercially available bulkfill composites. J Dent. 2014;42:e993-e1000.

11. Hahnel S, Dowling AH, El-Safty S, Fleming GJP. The influence of monomeric resin and filler characteristics on the performance of experimental resin-based composites (RBCs) derived from a commercial formulation. Dent Mater. 2012;28:e416-23.

12. Van Ende A, De Munck J, Van Landuyt KL, Poitevin A, Peumans M, Van Meerbeek B. Bulk-filling of high C-factor posterior cavities: Effect on adhesion to cavity-bottom dentin. Dent Mater. 2013;29:26977.

13. Abouelleil H, Pradelle N, Villat C, Attik N, Colon P, Grosgogeat B. Comparison of mechanical properties of a new fiber reinforced composite and bulk filling composites. Restor Dent Endod. 2015;40:262-70. 14. Shortall AC, Palin WM, Burtscher P. Refractive index mismatch and monomer reactivity influence on composite curing depth. J Dent Res. 2008;87:e84-8.

15. Ilie N, Hickel R. Investigations on a methacrylate-based flowable composite based on the SDRTM technology. Dent Mater. 2011;27:34855 .

16. Ilie N, Bucuta S, Draenert M. Bulk-fill resin-based composites: an in vitro assessment of their mechanical performance. Oper Dent. 2013;8:618-25.

17. Swapna MU, Koshy S, Kumar A, Nanjappa N, Benjamin S, Nainan MT. Comparing marginal microleakage of three Bulk Fill composites in Class II cavities using confocal microscope: An in vitro study. J Conserv Dent. 2015;18:409-13.
18. Johnston WM, Leung RL, Fan PL. A mathematical model for postirradiation hardening of photoactivated composite resins. Dent Mater. 1985;1:e191-4.

19. International standard ISO 4049-2009. Dentistry, Polymer-based restorative materials. Geneva: ISO. www.iso.org. [accessed 15.10.14] 20. Miyagawa Y, Powers JM, O'Brien WJ. Optical properties of direct restorative materials. J Dent Res. 1981;60:890-4.

21. Lee YK. Influence of filler on the difference between the transmitted and reflected colors of experimental resin composites. Dent Mater. 2008;24:1243-7.

22. Campbell PM, Johnston WM, O'Brien WJ. Light scattering and gloss of an experimental quartz-filled composite. J Dent Res. 1986;65:892-4.

23. Da Silva EM, Poskus LT, Guimaraes JGA. Influence of light polymerization modes on the degree of conversion and mechanical properties of resin composites: a comparative analysis between a hybrid and a nanofilled composite. Oper Dent. 2008;33:287-93.

24. Dickens S, Stansbury J, Choi K, Floyd C. Photopolymerization kinetics of methacrylate dental resins. Macromolecules. 2003;36:e604353.

25. Khatri CA, Stansbury JW, Schultheisz CR, Antonucci JM. Synthesis, characterization and evaluation of urethane derivatives of BisGMA. Dent Mater. 2003;19:e584-8.

26. Mills RW, Uhl A, Backwell GB, Jandt KD. High power light emitting diode (LED) arrays versus halogen light polymerization of oral biomaterials: Barcol hardness, compressive strength and radiometric properties. Biomaterials. 2002;23:e2955-63.

27. Yap AU, Seneviratne C. Influence of light energy density on effectiveness of composite cure. Oper Dent. 2001;26:e460-6.

\section{Conflict of Interest}

All authors declare no conflict of interests. 